\title{
Salty taste in dairy foods: Can we reduce the salt?
}

\author{
S. L. Drake, K. Lopetcharat, and M. A. Drake ${ }^{1}$ \\ Department of Food, Bioprocessing and Nutrition Sciences, Southeast Dairy Food Research Center, North Carolina State University, \\ Raleigh 27694
}

\section{ABSTRACT}

Sodium can be found in many sources of the US diet. Dietary guidelines currently suggest a maximum intake of $2,300 \mathrm{mg}$ of sodium ( $6 \mathrm{~g}$ of sodium chloride) per day, whereas the average consumer intake is $3,600 \mathrm{mg}$ of sodium (9 $\mathrm{g}$ of sodium chloride) per day. The main health concern with high consumption of sodium is hypertension. The objectives of this study were to identify the salty taste intensity of sodium chloride in water and various dairy food matrices, and to identify the just-noticeable difference in concentration at which consumers noticed a decrease in salty taste in these food products. Solutions and food products (water, cheese sauce, cottage cheese, and milk-based soup) were prepared with sodium chloride ranging in concentration from 0.008 to $0.06 M$. Seventeen panelists evaluated the salty intensity of each product in triplicate using a magnitude estimation scale. In subsequent tests, panelists $(\mathrm{n}=50)$ evaluated salty intensity of these food products in separate sessions using an ascending force choice method to determine the just-noticeable difference. Consumer acceptance tests ( $\mathrm{n}=75$ consumers) were conducted with cottage cheeses with and without sodium reductions and under conditions with and without health benefits of sodium reduction. The magnitude estimation scale data were log-transformed, and all data were analyzed by ANOVA with Fisher's least significant difference for means separation. The linear proportion of the power function in the salty taste intensity curve for sodium chloride solutions and the 3 foods was between 0.03 and $0.20 M$. Consumers were able to notice and correctly identify reductions in salt concentration of less than $20 \%$ in all products. When consumers were informed of sodium reduction and its health benefits before tasting cottage cheese with lower sodium (4-12\%), overall liking scores for the lower sodium cottage cheeses were not different from higher sodium cottage cheeses. These results suggest that reducing sodium in cheese sauce, cottage cheese, and milk-based soups may be challenging and that exploration of sodium chloride alternatives

Received June 6, 2010.

Accepted October 12, 2010.

${ }^{1}$ Corresponding author: mdrake@unity.ncsu.edu in these foods is warranted. Appropriate product positioning or advertising may be beneficial to consumer acceptance of lower sodium types of products.

Key words: sodium chloride, sensory, reduction, food application

\section{INTRODUCTION}

Sodium can be found in many sources of the US diet. Dietary guidelines currently suggest a maximum intake of $2,300 \mathrm{mg}$ of sodium per day ( $6 \mathrm{~g}$ of sodium chloride), whereas the average consumer intake is $9 \mathrm{~g}$ of sodium chloride (salt) per day. Most of the sodium $(\sim 75 \%)$ in the American diet is obtained from processed foods (USDA, 2005). Furthermore, the average American adds another 5 to $10 \%$ of their total salt intake from a salt shaker (USDA, 2005). Naturally occurring sources of sodium only make up about $10 \%$ of sodium within the diet (Johnson and Kumanyika, 2008). High dietary salt intake has health implications that include increases in body water weight, total exchangeable sodium extracellular fluid volume, and plasma volume (USDA, 2005), all of which contribute to hypertension. Because of high sodium intakes and other factors in the United States, approximately 65 million adults are considered to have hypertension (Bosworth et al., 2008). Hypertension is defined as having a blood pressure greater than 140/90 mmHg (Miller, 2003).

The FDA has many rules for labeling sodium on food products. According to the FDA, the term "healthy" can be stated on the food label only if the food contains no more than $480 \mathrm{mg}$ of sodium per serving (Stehlin, 1993). Meals and main dishes should have no more than $600 \mathrm{mg}$ (Stehlin, 1993). "Low sodium" foods should have $140 \mathrm{mg}$ or less than the reference serving size (Stehlin, 1993). Foods with "reduced or less sodium" labeling should have at least $25 \%$ less sodium than the reference food when the reference food is not considered a "low sodium" food (Stehlin, 1993).

In the mid 1980s, several studies evaluated replacement of sodium chloride with other salts due to the high correlation between salt $(\mathrm{NaCl})$ intake and hypertension. One salt of interest was potassium chloride because studies indicated that an increased intake of potassium via the diet could exert a protective effect in 
individuals with sodium-induced hypertension (Fregly, 1981; Lecos, 1983; Linas, 1991; Haddy, 2006). Several studies have suggested that some products such as cheese and fermented sausage can have up to $50 \%$ of the $\mathrm{NaCl}$ replaced with other salts without a significant effect on flavor (Katsiari et al., 1997; Guardia et al., 2006). However, considerable controversy exists regarding consumer acceptance of these products (Adams and Maller, 1995). Studies suggest that many factors play a role in salty taste perception, including fat, viscosity, spices, monosodium glutamate, and the microstructure of the food.

The need to manufacture processed products with reduced or low sodium content is growing. Low-sodium products are known to be bland, tasteless, and boring in flavor (Blais et al., 1986; Malherbe, 2003). Moreover, when consumers are accustomed to foods high in sodium (as most US consumers are), sodium reduction or changes due to sodium reduction may be more noticeable or objectionable. Our questions were 2-fold. First, can a small amount of sodium be reduced in dairy foods without consumers noticing or without it affecting acceptance? And second, does labeling sodium reduction in dairy foods improve consumer acceptance of these products? The objectives of this study were to identify the salty taste intensity of sodium chloride in water and various dairy food matrices and to identify the just-noticeable difference (JND) in concentration at which consumers noticed a decrease in salty taste in these food products and to determine the effect of labeling sodium reduction on consumer acceptance of reduced-sodium dairy foods.

\section{MATERIALS AND METHODS}

\section{Sample Preparation}

Three dairy products (milk-based soup, cottage cheese, and cheese sauce) along with deionized water were selected to evaluate sodium reduction. Deionized water was selected because it was the simplest matrix and was used as the control. Milk-based soup and cottage cheese were selected because they are common dairy-based products and the sodium and protein contents could be controlled experimentally. Cheese sauce was selected because salty taste is a primary driver of liking and a component of "cheesiness" perception for this product (Childs et al., 2009) and because it was a complex matrix with fat, sodium, proteins, and peptides, which may affect the perception of salty taste.

Milk-Based Soup. Soup was prepared using 591.0 $\mathrm{mL}$ of whole milk, $57.5 \mathrm{~g}$ of all-purpose flour, $30 \mathrm{~g}$ of unsalted butter, and salt (at various concentrations). Butter was melted and flour was added to make a roux; then, milk was added and the mixture was brought to a boil.

Cottage Cheese. Cream dressing (10 kg) was prepared with an $8 \%$ milkfat mixture prepared from raw cream and skim milk. Stabilizer $(0.45 \%$ wt/vol; TIC Gums, Baltimore, MD) was added and the mixture was heated to $85^{\circ} \mathrm{C}$ for 15 min followed by homogenization (model NS1001L2K, GEA Nitro Soavi, Parma, Italy) at $200 \mathrm{bar}(20,000 \mathrm{kPa})$. The mix was then batch-pasteurized at $85^{\circ} \mathrm{C}$ for $30 \mathrm{~min}$, cooled to $4^{\circ} \mathrm{C}$, and stored overnight at $4^{\circ} \mathrm{C}$. Salt was added at various concentrations. Finally, the dressing and cottage cheese curds (Daisy Brand, Garland, TX) were mixed in a 50:50 ratio to a final fat content of $4 \%$ (wt/wt).

Cheese Sauce. Cheese sauce was prepared using $226.8 \mathrm{~g}$ of grated medium Cheddar cheese (purchased locally), $236.5 \mathrm{~mL}$ of whole milk, $30 \mathrm{~g}$ of unsalted butter, $30 \mathrm{~g}$ of all-purpose flour, and salt (at various concentrations). Unsalted butter was melted on the stove top in a pot and flour was added to make a roux; then, milk was added and the mixture was brought to a boil. Grated cheese was added until thoroughly melted. The salinity of the base cheese sauce was measure using a chloride analyzer (SAT-500, DKK-TOA Corp., Tokyo, Japan). The chloride concentrations were then calculated as \% (wt/wt) in $\mathrm{NaCl}$.

\section{Power Function of Saltiness in Different Media}

All sensory analyses were conducted in compliance with North Carolina State University Institutional Review Board (NCSU IRB) for human subject regulations. Food-grade sodium chloride was $>99 \%$ pure (Fisher Scientific, Pittsburgh, PA). Seventeen panelists (15 females and 2 males, ages 25 to $35 \mathrm{yr}$ ) were utilized for this activity. Each panelist received $5 \mathrm{~h}$ of training in salty taste identification and in how to use magnitude estimation scaling (MES; Meilgaard et al., 1999). The starting sodium concentrations in each food matrix were different based on the most common concentrations that were found in the market place. Cottage cheese sodium concentrations were based on $450 \mathrm{mg}$ per $1 / 2$ cup (113 g) serving. Milk-based soup sodium concentrations were based on $900 \mathrm{mg}$ per $1 / 2$ cup (120 $\mathrm{mL}$ ) serving. Cheese sauce was more difficult because of the use of natural Cheddar cheese, which contained 180 $\mathrm{mg}$ of sodium per $28 \mathrm{~g}$; therefore, the sodium content had to be doubled ( $360 \mathrm{mg}$ sodium per $28 \mathrm{~g}$ ) to be able to identify 1 JND with regards to a sodium reduction.

For magnitude estimation, subjects were instructed to taste a reference sample $(0.07 M)$ each time they evaluated solutions. This reference was assigned a value of 10 in salty taste intensity. This reference was used to simplify instructions and to avoid problems in the 
need for normalization of data (Pearce et al., 1986). Subsequent samples were rated in proportion to the perceived intensity of this reference; for example, if a sample tasted twice as salty as the reference, it was rated 20. Subjects retasted the reference after each sample. All products were placed into lidded $58-\mathrm{mL}$ soufflé cups with random 3-digit codes. The samples were prepared $18 \mathrm{~h}$ before testing and were stored overnight at $3^{\circ} \mathrm{C}$. Before serving, solutions were equilibrated to room temperature $\left(21^{\circ} \mathrm{C}\right)$. Approximately $30 \mathrm{~mL}$ of each sample was presented in lidded 58 -mL soufflé cups. The serving order of samples was randomized. All products with varying salt concentrations were evaluated in triplicate and each product type was evaluated separately. Salty taste intensity profiling was conducted in sessions on 9 different days.

\section{Difference Threshold Testing}

A difference threshold is the amount of change in a stimulus (in this case, sodium) necessary to produce a noticeable difference, which is often called the justnoticeable difference (Delwiche, 2009). A difference threshold is quite similar to a detection threshold, but instead of looking for the lowest intensity that can cause a sensation, this study was looking for the lowest decrease in stimulation (sodium content) compared with the base intensity that would cause a change in salty taste. Water solutions and food products were prepared as described above; however, the starting salt concentrations selected were based on the sodium concentration found in commercial products. The starting salt concentration for cottage cheese was 0.71 $\mathrm{g}$ of salt per 113-g serving or $450 \mathrm{mg}$ of $\mathrm{Na}$ per 113$\mathrm{g}$ serving, and $1.43 \mathrm{~g}$ of salt per $120-\mathrm{mL}$ serving or $900 \mathrm{mg}$ of Na per 120-mL serving for milk-based soup and water, and $0.57 \mathrm{~g}$ of salt per $28 \mathrm{~g}$ or $360 \mathrm{mg}$ of $\mathrm{Na}$ per $28 \mathrm{~g}$ of cheese sauce. Sodium reductions were then calculated for these starting concentrations. Both milk-based soup and cheese sauce sodium reductions were in $5 \%$ (wt/vol) increments up to $35 \%$, whereas cottage cheese and water solution sodium reductions were in $3 \%$ increments up to $21 \%$. Small increments in sodium reductions were examined because we wanted to detect the JND between samples. Water and cottage cheese had smaller sodium reduction increments because the product matrices were very simple, whereas milk-based soup and cheese sauce had larger sodium reduction increments because these matrices are more complicated and higher in fat, which may suppress salty taste perception. All samples were placed into 58-mL soufflé cups coded with 3-digit random codes and presented at room temperature. A modification of the ASTM procedure E679-9 (ASTM, 1992), a 7-series ascending forced choice method of limits, was used to determine the JND threshold for each product. Subjects $(n=50)$ were instructed before testing. Subjects wore a nose clip (A-M Systems Inc., Sequim, WA) and were instructed to taste each sample in each cup in the series. Subjects were told to thoroughly disperse the samples within their mouths. Subjects rested $1 \mathrm{~min}$ between each set and were also instructed to rinse their mouths with spring water and to take a bite of unsalted cracker between cups. Subjects were asked to choose the 1 item from the 3 that they thought was different. The magnitudes of differences between the reference concentration and test concentrations were represented in term of d-prime values calculated from Thurstonianbased modeling for 3-Alternative Force Choice (Ennis et al., 1988; O'Mahony et al., 1994; Ennis, 1998).

\section{Consumer Acceptance}

Consumer acceptance testing was conducted on cottage cheese with and without a sodium reduction in the cream dressing to determine how sodium reduction affected acceptance and to determine how labeling of sodium reduction affected consumer acceptance of this product. The sodium concentrations tested were based on the JND results. Four cottage cheeses were prepared using the methods described previously: no reduction $(0.71 \mathrm{~g}$ of salt per $113 \mathrm{~g}$ serving or $450 \mathrm{mg}$ of Na per $113-\mathrm{g}$ serving), $4 \%$ reduction ( $0.68 \mathrm{~g}$ of salt per 113 -g serving or $432 \mathrm{mg}$ of Na per 113-g serving), $8 \%$ reduction $(0.65 \mathrm{~g}$ of salt per $113-\mathrm{g}$ serving or $414 \mathrm{mg}$ of Na per 113-g serving), and $12 \%$ reduction in sodium (0.62 g of salt per 113-g serving or $396 \mathrm{mg}$ of $\mathrm{Na}$ per 113-g serving). Three different ballots were designed to evaluate the cottage cheeses: traditional ballot, priming ballot, and priming plus benefit ballot. All ballots evaluated consumer perception of cottage cheese for overall acceptance, appearance liking, cottage cheese flavor liking, salty taste liking, salty taste intensity, and texture liking using a 9-point hedonic/intensity scale, where $1=$ dislike extremely or low intensity and $9=$ like extremely or high intensity. A just-about-right (JAR) scale was also used to evaluate salty taste. The JAR scale was a 5-point agreement scale with the center point being just about right, the left anchor being too little of the attribute and the right anchor being too much of the attribute (Meilgaard et al., 1999). Each ballot also had a purchase intent, using a 5-point scale, where $1=$ definitely would not buy and $5=$ definitely would buy. The priming ballot asked the same questions as the traditional ballot, but informed consumers that some of the cottage cheeses were reduced in sodium. The priming plus benefit ballot asked the same questions as the traditional ballot, but informed consumers that 
some of the cottage cheeses were reduced in sodium and that the health benefits associated with lower sodium included "reduced high blood pressure" and "reduced heart disease" risk.

Self-reported consumers (defined as consumers that purchased and consumed cottage cheese at least monthly; $\mathrm{n}=75$ ) of cottage cheese were recruited from the university students, staff, and faculty through e-mails and fliers. The same consumers were recruited for 3 different days of testing and 1 mo elapsed between consecutive days of testing to prevent issues from memory or adaptation. Three days of testing were used because the 3 different ballots (traditional ballot, priming ballot, and priming plus benefit ballot) were used to test the same 4 cottage cheeses with the same consumers in a crossover design.

For each day of testing, the 4 cottage cheeses (no reduction, and 4,8 , and $12 \%$ reductions in sodium) were tested in a single session with a 2 -min enforced rest between each sample. Panelists were provided with deionized water and unsalted crackers for palate cleansing. Thirty grams of each cottage cheese was dispensed into a lidded 58-mL soufflé cup (numbered with 3 -digit code); the cottage cheeses were served at $10^{\circ} \mathrm{C}$. Consumers $(\mathrm{n}=75)$ were provided with consent forms consistent with NCSU Human Subjects approval and 1 of the 3 scoring ballots. The ballot that each consumer received for each session was randomized (crossover design, some consumers received the regular ballot in the first session, some the priming ballot, and some the priming plus benefits ballot). On the third and final day of consumer testing, a screener form for collecting demographic information and evaluating consumer decisions for cottage cheeses was given at the end of the tasting. Cottage cheeses were presented individually in a William's design within each ballot. Responses were collected using Compusense Five v4.8 (Compusense, Guelph, Ontario, Canada). Panelists were provided with gift certificates for their participation.

\section{Statistical Analysis}

The MES data were log-transformed, and data were analyzed by ANOVA with Fisher's least significant difference (LSD) for means separation. Fisher's LSD is known to result in an increased risk of type I errors, but it is a sensitive and powerful post hoc test and was deemed appropriate for the study objectives. The power functions were constructed using simple linear regression between $\log _{10}$ [concentration] (x-axis) and $\log _{10}$ [perceived intensity from MES] (y-axis) using XLSTAT (version 10, Addinsoft, New York, NY). The JND data were analyzed using Thurstonian-based modeling for 3-Alternative Force Choice (3-AFC;
Ennis, 1998) using IFProgram (version 7.9, Institute of Perception, Richmond, VA). Consumer data were evaluated by ANOVA with means separation using the PROC MIXED command of SAS software (version 9.1, SAS Institute Inc., Cary, NC). Significant interactions (treatment $\times$ ballot) were individually sliced by treatment and ballot to determine which treatment or ballot format was responsible for the significant interactions. Penalty analysis was performed on overall liking scores based on JAR question responses using XLSTAT.

\section{RESULTS}

\section{Power Function of Saltiness in Different Media}

Salty taste perception was different among the different food products $(P<0.05)$ (Figure 1). The linear proportion of the power function in the salty taste intensity curve was between 0.03 and $0.20 M(20$ and $120 \mathrm{~g} / \mathrm{kg})$ for sodium chloride water solution, $4 \%$ cottage cheese, and milk-based soup. However, the linear proportion of the power function in salty taste for cheese sauce was between 0.06 and $0.20 M(40$ and $120 \mathrm{~g} / \mathrm{kg}$ ). The exponents of the power functions reveal the perception of saltiness in different media and allow researchers to estimate the iso-saltiness concentrations between different media. The exponent for milk-based soup (1.53) was similar that to for water $(1.56 ; P>0.05)$, whereas the exponent for cheese sauce $(1.31)$ was lower $(P<$ $0.05)$ than that of water solution, which suggests that it would take more of a reduction in sodium in cheese sauce for the subjects to increase the perception of salty taste. This makes sense because cheese sauce is a more complicated matrix with fat, protein, and peptides and other volatile aromatics and other basic tastes including umami that can mask, compete with, or even inhibit the perception of salty taste. On the other hand, cottage cheese had a steeper exponent $(2.23 ; P<0.05)$ compared with water or the other foods, which suggests that it will take less reduction in sodium for consumers to increase the intensity of salty taste in this product compared with the other products. Cottage cheese is a mildly flavored product with cooked/milky and milkfat flavors and salty taste as predominant attributes (Drake et al., 2009). Changes in salty taste might be expected to be more noticeable compared with other products.

\section{JND Threshold Testing}

As expected, panelists were able to differentiate different percentages of salt reduction in the different food matrices. The first JND of $900 \mathrm{mg}$ of $\mathrm{Na}$ in water was $878 \mathrm{mg}$ of $\mathrm{Na}$, which was only a $2 \%$ reduction in sodium. The first JND of $450 \mathrm{mg}$ of Na per $113 \mathrm{~g}$ in $4 \%$ cottage 


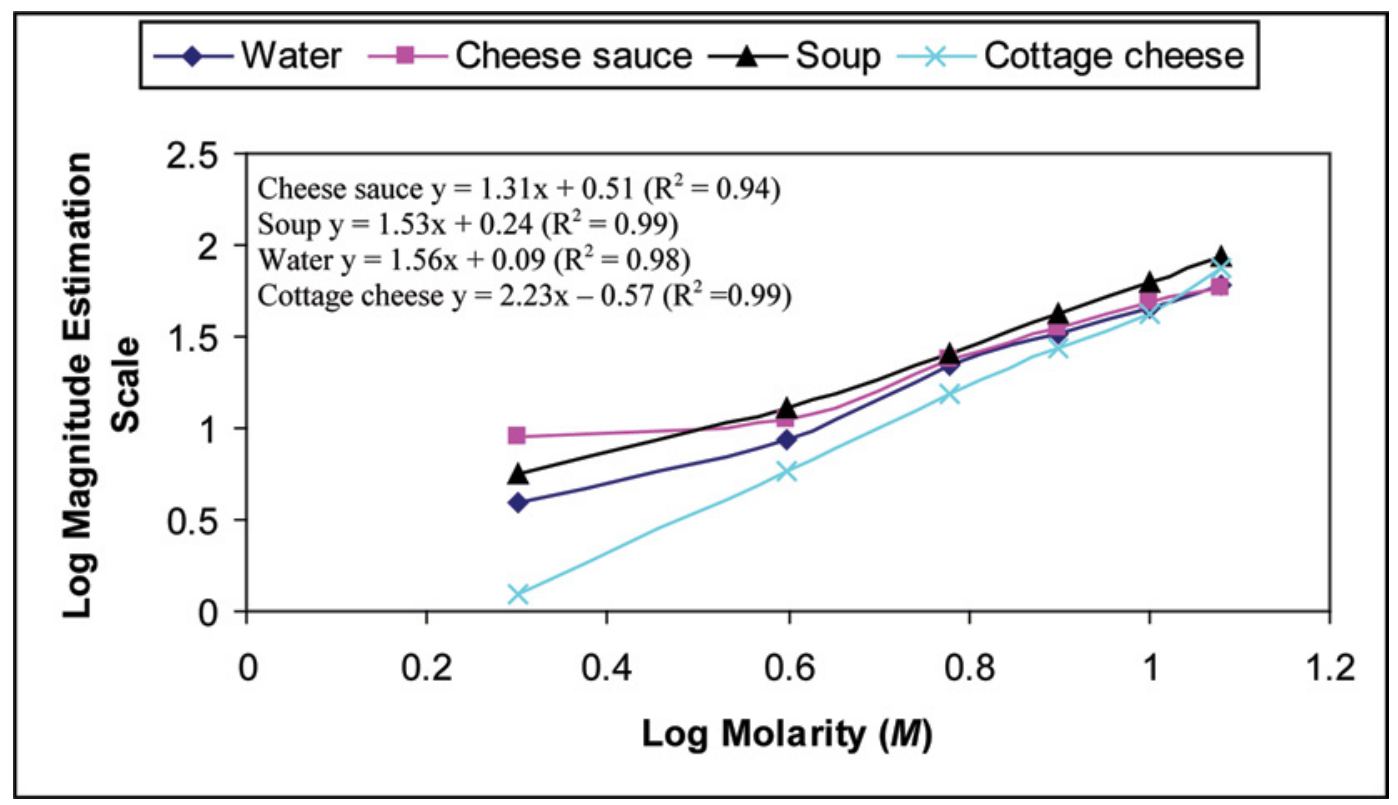

Figure 1. Salty taste intensity perception in water and different food matrices using the log-transformation of the magnitude estimation scale versus molar concentration of salt solutions. Color version available in the online PDF.

cheese was $414 \mathrm{mg}$ of $\mathrm{Na}$, which is an $8 \%$ reduction in sodium. In a milk-based soup matrix, the first JND of $900 \mathrm{mg}$ of $\mathrm{Na}$ per $120 \mathrm{~mL}$ of soup was $762 \mathrm{mg}$ of $\mathrm{Na}$, which is a $15 \%$ reduction in sodium. For cheese sauce with $360 \mathrm{mg}$ of Na per $28 \mathrm{~g}$, the first JND was $309 \mathrm{mg}$ of $\mathrm{Na}$, which is a $14 \%$ reduction in sodium. However, it is important to remember that JND are only relevant for products with that starting sodium content and, as was the case with cheese sauce, we had to double the sodium content because we were using natural Cheddar cheese that already had a sodium content of $180 \mathrm{mg}$ of $\mathrm{Na}$ per $28 \mathrm{~g}$. By doubling the sodium content in cheese sauce, we complicated the JND issue because the amount of stimulus added to the baseline increases as the intensity level of the baseline is raised (Delwiche, 2009). Therefore, this JND is only good for cheese sauce with a starting sodium level of $360 \mathrm{mg}$ of $\mathrm{Na}$ per $28 \mathrm{~g}$. These data suggest that, like the salty taste intensity curves, more sodium can be removed without perceived differences with a more complicated food matrix.

\section{Consumer Acceptance}

Cottage cheese was selected for consumer testing because the power function and JND data suggested that it would take smaller reduction in sodium for consumers to notice a difference in salty taste. Cottage cheese is also a matrix in which it is easy to control sodium content and present to consumers. Cottage cheese consumers differed in gender $(20 / 80 \%$, male/female), age $(3,20$,
45,30 , and $2 \%$ were $18-24,25-30,31-45,45-50$, and $>51 \mathrm{yr}$, respectively), types of cottage cheese consumed $(5,15,40$, and $40 \%$ for fat free, low fat (1\%), reduced fat $(2 \%)$, and full fat, respectively), usage of cottage cheese $(55,45,55,20,27$, and $5 \%$ were the frequencies of consumption as snack, on salad, with fruit, breakfast, ingredient, and other), and factors influencing choice/ purchase of cottage cheese $(66,40$, and $73 \%$ were the frequencies for price, brand, and flavor, respectively) (all $P<0.05$ ). All consumers purchased and consumed cottage cheese at least monthly. Consumers were not on any kind of dietary restriction, including sodium. This question was important because consumers who are already on low-sodium diets are more sensitive to salt than consumers not on low-sodium diets (Bertino et al., 1982; Blais et al., 1986). No interaction was found among the reduced-sodium cottage cheese treatments and the ballots for overall liking, appearance liking, flavor liking, or salty taste intensity $(P>0.05)$. In general, no differences were found between the control (no sodium reduction) cottage cheese up to an $8 \%$ sodium reduction, but a difference was found between the control cottage cheese and $12 \%$ sodium reduction for overall acceptance, appearance liking, flavor liking, and salty intensity (Figure 2).

An interaction $(P<0.05)$ was found between type of ballot and sodium-reduction treatment for salty taste and texture liking, and purchase intent. This result was expected because it has been documented that consumer opinions are influenced by how much information has 


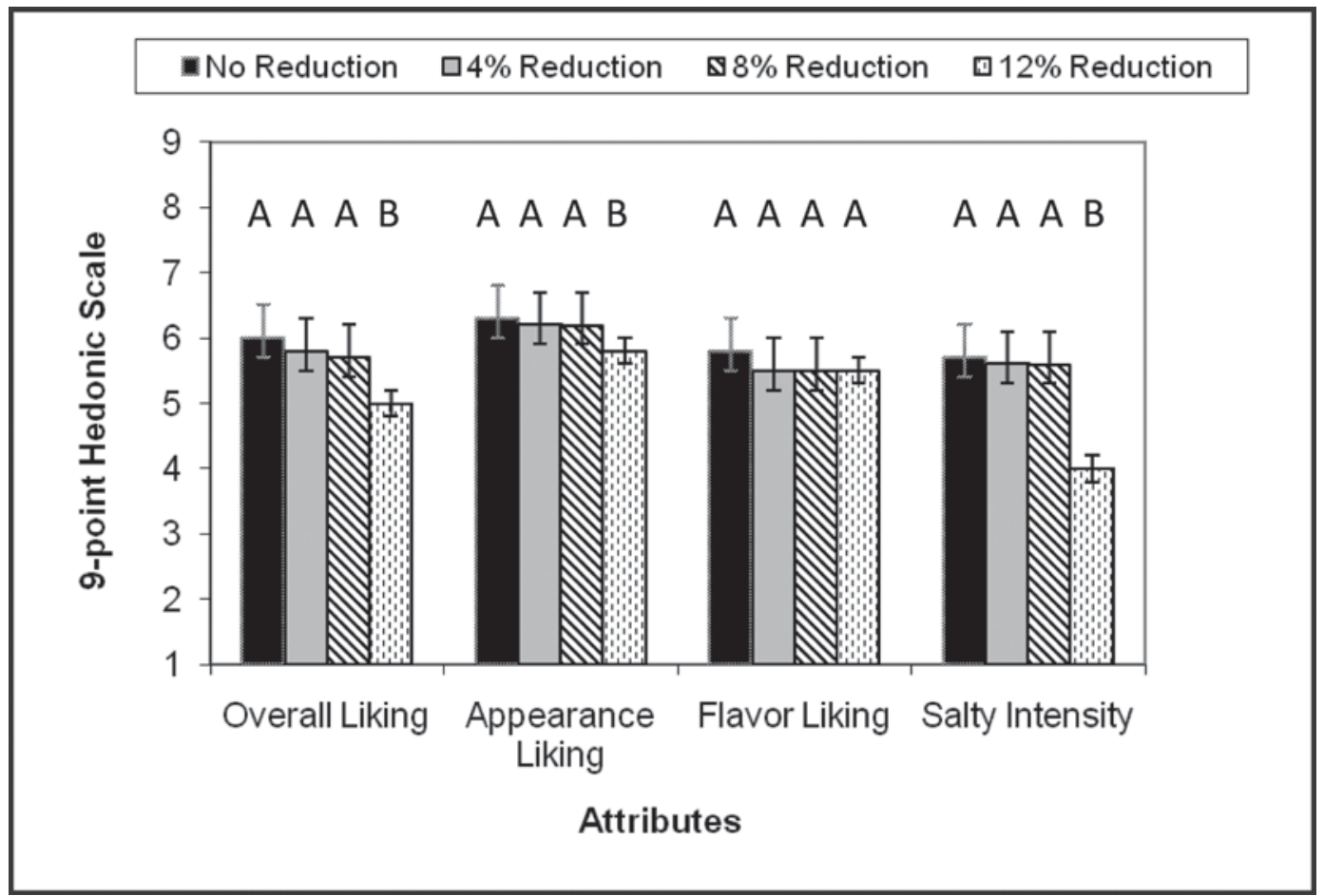

Figure 2. Consumer means for cottage cheese attributes that did not have an interaction with varying sodium reductions. The control cottage cheese (no reduction) contained $450 \mathrm{mg}$ of sodium. Intensities were scored using a 9-point scale where $1=$ dislike extremely and $9=$ like extremely. Different letters indicate a significant difference $(P<0.05)$.

been presented to them about the products before tasting (Bowers et al., 2003; Cho et al., 2005). In general, consumers scored salty taste liking lower as the sodium was reduced in cottage cheese when using the traditional ballot (no information provided) and the priming ballot (informed that products may have sodium reduction). However, when consumers were exposed to the priming and benefits ballot, consumers did not score the $12 \%$ reduced-sodium cottage cheese as low in salty taste liking as when presented this product with the traditional blinded ballot (Figure 3 ). When it came to texture liking, no differences were observed in texture liking when using the traditional ballot (no information provided) and the priming plus benefit ballot, but when consumers used just the priming ballot (informed that products may have sodium reduction) all samples scored significantly lower in texture liking (Figure 4). It has been noted that salt does play a role in texture of food (Stampanoni and Noble, 1991; Mistry and Kasperson, 1998). However, decreased texture liking may also be associated with an element of expectation from the consumer that any product that has a reduction in a desirable attribute (e.g., fat or sodium) has decreased liking in other properties such as texture (Shamil et al., 1992; Wendin et al., 2000). Consumers scored purchase intent higher for the $12 \%$ reduced-sodium cottage cheese when they were exposed to the priming and benefits ballot than to the traditional blind ballot (Figure 5), as would be expected because research has shown that priming influences consumers to score products higher than they would if blinded to information about the product (Bowers et al., 2003; Cho et al., 2005).

Penalty analysis using JAR responses and overall liking scores were consistent with liking scores. When the cottage cheeses did not meet consumer expectations in salty taste consumers lowered their overall liking scores. Penalty analysis revealed that treatments 3 (8\% reduction) and 4 (12\% reduction) were penalized in overall liking scores, on average, 1.7 and 1.7 for too little salty taste, respectively, when using the traditional ballot. However, when consumers had the primed ballot or the primed plus benefit ballot before tasting, penalty analysis revealed that only the $12 \%$ reduction treatment was penalized in overall liking scores (mean of 2.0 for too little salty taste).

\section{DISCUSSION}

Consumers in the United States are very accustomed to foods with salty taste and when the salt is decreased, consumers find this objectionable (Malherbe, 2003). Food industries are being pushed to reduced sodium 


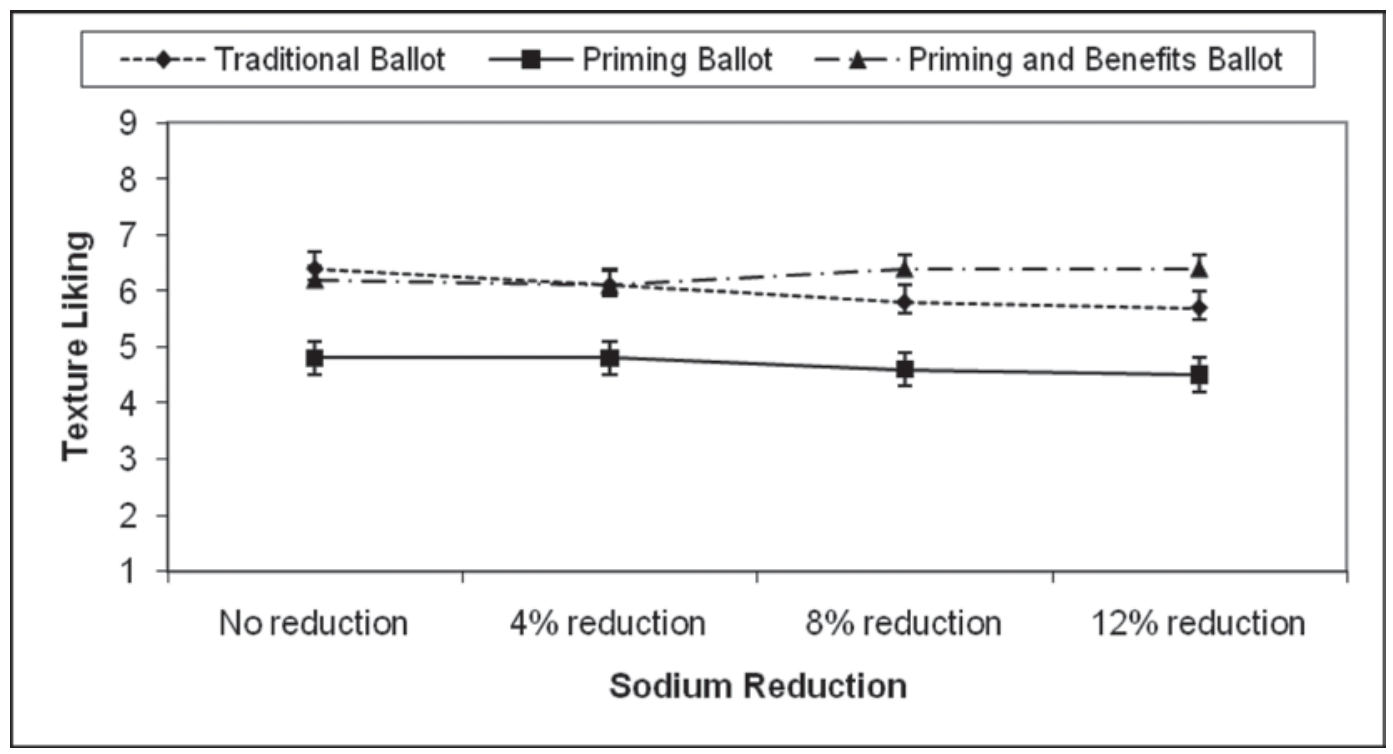

Figure 3. Salty taste liking for each cottage cheese treatment using the 3 different ballots (traditional ballot, priming ballot, and priming and benefits ballot). Intensities were scored using a 9 -point scale where $1=$ dislike extremely and $9=$ like extremely.

in their food products to help reduce the health implications (hypertension, coronary disease, and stroke) that have been linked to high-salt diets (Law, 1997). It has been reported that consumers view low-sodium products as bland, tasteless, and boring in flavor (Malherbe 2003). Further, a high-sodium diet may lead consumers to have a preference for high-sodium foods (Kim and Lee, 2009). A study conducted by Kim and Lee (2009) found that participants who reported a liking for soups or stews that were high in sodium
(1,000 mg/serving) had significantly higher thresholds for $\mathrm{NaCl}(P=0.029)$, and frequent users of fast-food restaurants showed a preference for significantly saltier soup $(P=0.010)$ compared with those who were not frequent fast-food consumers. The preferred salt level was associated significantly with a high preference for pizza $(P=0.018)$ or hamburgers $(P=0.010)$ and the frequent consumption of pork cutlets $(P=0.046)$ or hamburgers $(P=0.010)$. Because of high exposure to sodium, consumers will probably notice a $25 \%$ reduc-

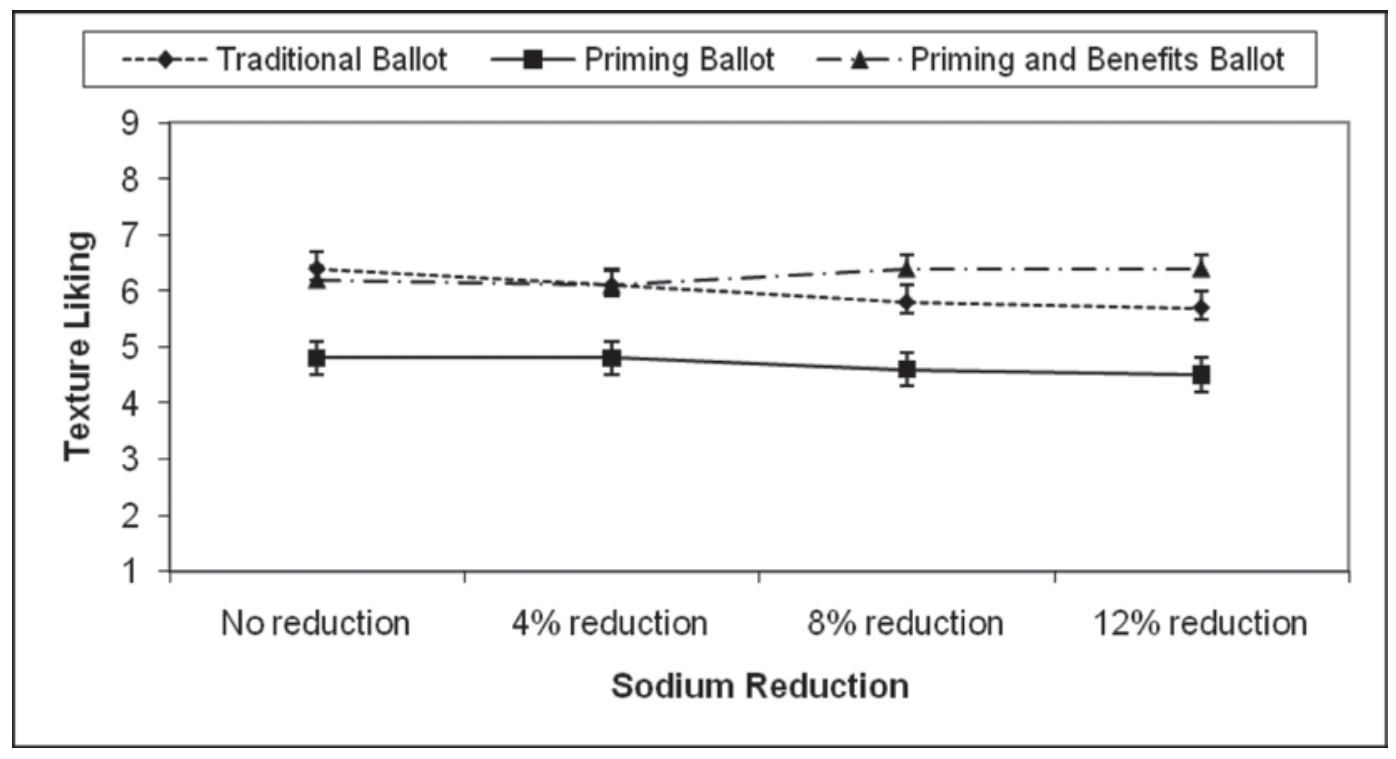

Figure 4. Texture liking for each cottage cheese treatment using the 3 different ballots (traditional ballot, priming ballot, and priming and benefits ballot). Intensities were scored using a 9 -point scale where $1=$ extremely dislike and $9=$ extremely like. 


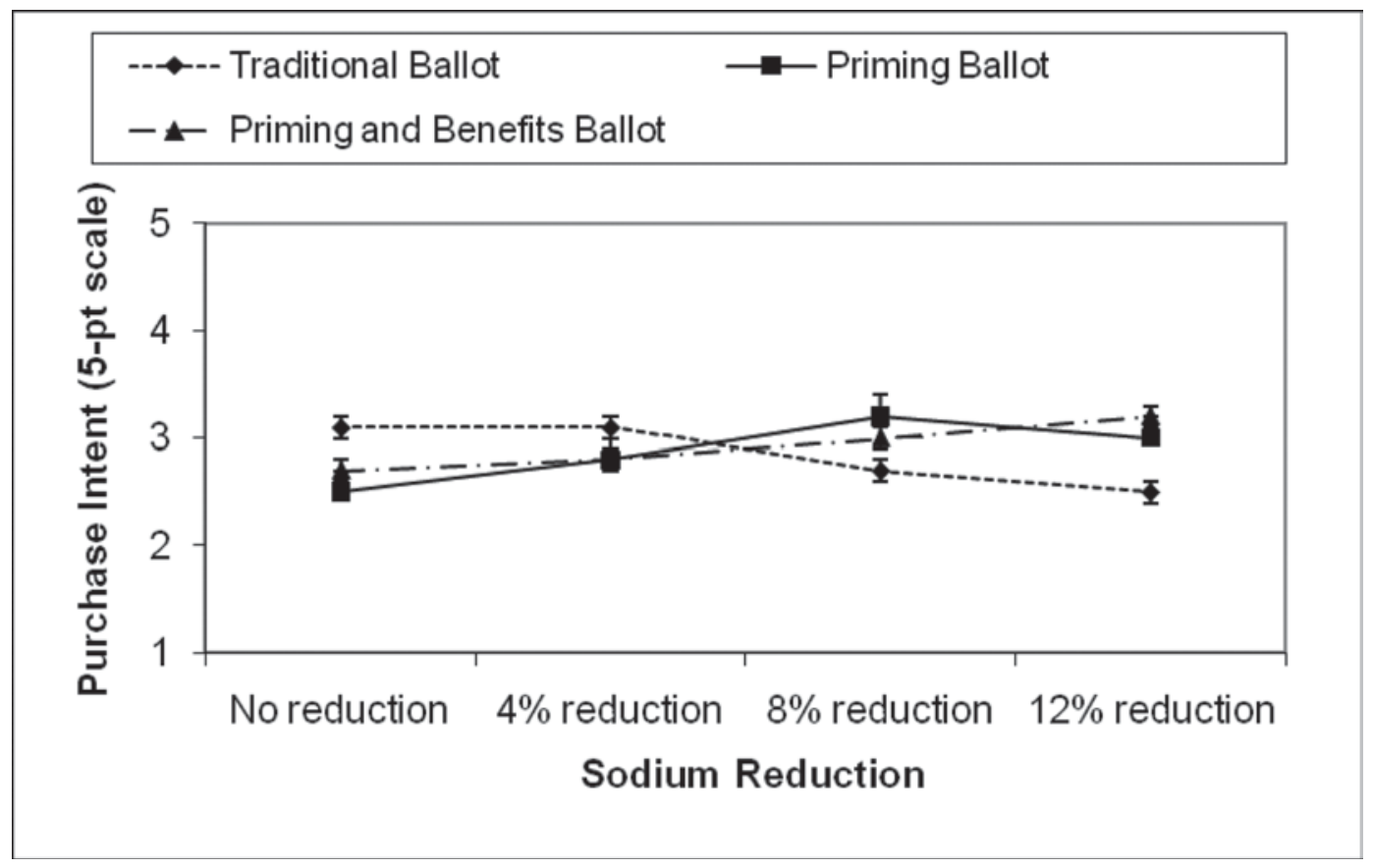

Figure 5. Purchase intent for each cottage cheese treatment using the 3 different ballots (traditional ballot, priming ballot, and priming and benefits ballot). Intensities were scored using a 5 -point scale where $1=$ definitely would not buy and $5=$ definitely would buy.

tion in most products; therefore, the food industry has talked about slowly reducing the salt in products over time to help maintain consumer loyalty (Fletcher, 2007). The current study demonstrates that different amounts of sodium can be removed from different products without consumers noticing. The complexity of the food matrix appears to help mask sodium reductions as was the case with cheese sauce and milk-based soup. This is good news because cheese sauce is an ingredient used in many food products; however, reducing the sodium significantly could cost the food industry consumer loyalty because one driver of liking for this product is salty taste (Childs et al., 2009). A small sodium reduction $(<18 \%)$ in this product would not necessarily be noticed by consumers. Similarly, small sodium reductions $(<15 \%)$ in milk-based soups may not be noticed and this could be due to several factors such as temperature and viscosity along with interactions occurring in the matrix such as fat, protein, and minerals. Temperature plays a role in salty taste perception and this is an important component of soups. Previous research has shown that subjects were more sensitive to saltiness of $\mathrm{NaCl}$ solutions in a middle temperature range $\left(20-40^{\circ} \mathrm{C}\right)$ compared with either colder or hotter solutions (Pangborn et al., 1970; McBurney et al., 1973; Paulus and Reisch, 1980). Another factor in soups and sauces is the type of thickener used because these will strongly influence salty taste and viscosity. Xanthan gum has been shown to suppress salty taste even with endogenous $\mathrm{Na}^{+}$(Rosett et al., 1994, 1995, 1996), whereas sodium-carboxymethyl cellulose (NaCMC) contributes considerable $\mathrm{Na}^{+}$to the systems $(61$ mg per $240-\mathrm{mL}$ serving), which would be undesirable in reduced-sodium foods. A recent study conducted by Lawrence et al. (2009) found that odor may influence saltiness perception in foods. In the first experiment, 81 consumers indicated expected taste attributes for written descriptions of flavors of common food items. The panelists rated expected saltiness of flavor evoked by the written description, which resulted in differences in expected saltiness in relation to actual salt content of food. In the second part of the experiment, commercially available aromas corresponding to 14 of the salt-associated flavors chosen in the first experiment were prepared in water solutions that did or did not contain sodium chloride. Fifty-nine of the panelists rated odor and taste (bitterness, sourness, saltiness, and sweetness) intensity orthonasally and retronasally. Researchers found that expected flavors could induce saltiness and enhance saltiness in solutions containing a low level of sodium chloride through odor-induced changes in taste perception, suggesting that selected odors might enhance perceived saltiness in sodiumchloride reduced food.

Consumer education and labeling may also play a critical role in acceptance of foods with reduced sodium. Cottage cheese is a mild-tasting dairy food of which salty taste is a key attribute. Not surprisingly, 
consumers noticed a difference in salty taste in this food with a decrease in sodium of $8 \%$. However, consumer testing revealed that overall liking or salty taste liking scores were not affected until a $12 \%$ sodium reduction. Wyatt (1983) reported that a $25 \%$ sodium reduction in cottage cheese did not result in a difference in overall liking, texture liking, and flavor liking; however, this study used only 40 panelists. Labeling plays a key role in consumer acceptance of products. Consumers tend to look upon products more favorably if there is justification for the reduction of certain attributes. In our study, consumers were more accepting of reducedsodium cottage cheese when the health benefits were associated with the product. Good labeling and marketing of reduced-sodium products and health benefits will enhance consumer acceptance.

\section{CONCLUSIONS}

Small reductions (2 to $5 \%$ ) in sodium were not noticeable by consumers. Complexity of the food matrix influenced salty taste perception and the percentage sodium reduction that was noticeable to consumers. Presentation of the health benefits of sodium reduction enhanced consumer acceptance. Small reductions in sodium over time may be one solution to lowering sodium in products without losing consumer loyalty especially for products that have a very simple matrix. Further research in understanding the role of individual components of the food matrix in salty taste may help to further clarify salty taste perception.

\section{ACKNOWLEDGMENTS}

This study was funded in part by Dairy Management Inc. (Rosemont, IL). This is Manuscript FSR 10-33 of the Department of Food, Bioprocessing and Nutrition Sciences, North Carolina State University. The use of trade names does not imply endorsement or lack of endorsement by those not mentioned.

\section{REFERENCES}

Adams, S. O., and O. Maller. 1995. Consumer acceptance of foods lower in sodium. J. Am. Diet. Assoc. 95:447-453.

ASTM. 1992. Standard practice for determination of odor and taste thresholds by a force-choice method of limits. E679-91. Pages 3539 in Annual Book of Standards. American Society for Testing and Materials, Philadelphia, PA.

Bertino, M., G. K. Beauchamp, and K. Engelman. 1982. Long-term reduction in dietary sodium alters the taste of salt. Am. J. Clin. Nutr. 36:1134-1144

Blais, C. A., R. M. Pangborn, N. O. Borhani, and F. M. Ferrel. 1986. Effect of dietary sodium restriction on taste responses to sodium chloride a longitudinal study. Am. J. Clin. Nutr. 44:232-243.

Bosworth, H. B., M. K. Olsen, A. Neary, M. Ori, J. Grubber, L. Svetkey, M. Adams, and E. Z. Oddone. 2008. Take control of your blood pressure (TCYB) study: A multifactorial tailored behavioral and educational intervention for achieving blood pressure control. Patient Educ. Couns. 70:338-347.

Bowers, J. A., M. A. Saadat, and C. Whitten. 2003. Effect of liking, information and, consumer characteristics on purchase intention and willingness to pay more for a fat spread with a proven health benefit. Food Qual. Prefer. 14:65-74.

Childs, J. L., M. D. Yates, and M. A. Drake. 2009. Sensory properties and consumer perception of wet and dry cheese sauces. J. Food Sci. 74:S205-S218

Cho, H. Y.. S. J. Chung, H. S. Kim, and K. O. Kim. 2005. Effect of sensory characteristics and non-sensory factors on consumer liking of various canned tea products. J. Food Sci. 70:S532-S538.

Delwiche, J. 2009. Psychological considerations in sensory analysis. Pages 7-15 in The Sensory Evaluation of Dairy Products. 2nd ed. S. Clark, M. Costello, M. A. Drake, and F. Bodyfelt, ed. Springer, New York, NY

Drake, S. L., K. Lopetcharat, and M. A. Drake. 2009. Comparison of two different methods to predict consumer preference of cottage cheese. J. Dairy Sci. 92:5883-5897.

Ennis, D. M. 1998. Thurstonian scaling for difference tests. IFPress $1: 2-3$.

Ennis, D. M., K. Mullen, and J. E. Frijters. 1988. Variants of the method of triads: Unidimensional Thurstonian models. Br. J. Math. Stat. Psychol. 41:25-36.

Fletcher, A. 2007. Real-progress in salt reduction claims. PepsiCo. Accessed March 24, 2010. http://www.foodnavigator.com/ScienceNutrition/Real-progress-in-salt-reduction-claims-PepsiCo.

Fregly, M. J. 1981. Sodium and potassium. Annu. Rev. Nutr. 1:6993.

Guardia, M. D., L. Guerrero, J. Gelabert, P. Gou, and J. Arnau. 2006 Consumer attitude towards sodium reduction in meat products and acceptability of fermented sausages with reduced sodium content. Meat Sci. 73:484-490.

Haddy, F. J. 2006. Role of dietary salt in hypertension. Life Sci. 79:1585-1592.

Johnson, G. H., and S. Kumanyika. 2008. Sodium. Accessed February 14, 2009. http://jn.nutrition.org/nutinfo/content/sodi.shtml.

Katsiari, M. C., L. P. Youtsinas, E. Alichanidis, and I. G. Roussis. 1997. Reduction of sodium content in feta cheese by partial substitution of $\mathrm{NaCl}$ by KCl. Int. Dairy J. 7:465-472.

Kim, G. H., and H. M. Lee. 2009. Frequent consumption of certain fast foods may be associated with an enhanced preference for salt taste. J. Hum. Nutr. Diet. 22:475-480.

Law, M. R. 1997. Epidemiologic evidence on salt and blood pressure. Am. J. Hypertens. 10:42S-45S.

Lawrence, G., C. Salles, C. Septier, J. Busch, and T. Thomas-Danguin. 2009. Odour-taste interactions: A way to enhance saltiness in lowsalt content solutions. Food Qual. Prefer. 20:241-248.

Lecos, C. 1983. Potassium: Keeping a delicate balance. FDA Consum $17: 20-23$.

Linas, S. L. 1991. The role of potassium in the pathogenesis and treatment of hypertension. Kidney Int. 39:771-786.

Malherbe, M. 2003. Consumer acceptability and salt perception of food with a reduced sodium content. J. Fam. Ecol. Consum. Sci. $31: 8$.

McBurney, D. H., V. B. Collings, and L. M. Glanze. 1973. Temperature dependence of human taste responses. Physiol. Behav. 11:89-94.

Meilgaard, M. M., G. V. Civille, and B. T. Carr. 1999. Selection and training of panel members. Pages 135-183 in Sensory Evaluation Techniques. 2nd ed. CRC Press, Boca Raton, FL.

Miller, N. H. 2003. Aggressive blood pressure management. J. Cardiovasc. Nurs. 18:108-115.

Mistry, V. V., and K. M. Kasperson. 1998. Influence of salt on the quality of reduced fat Cheddar cheese. J. Dairy Sci. 81:1214-1221.

O'Mahony, M., S. Masuoka, and R. Ishii. 1994. A theoretical note on difference tests: Models, paradoxes and cognitive strategies. J. Sens. Stud. 9:247-272.

Pangborn, R. M., R. B. Chrisp, and L. A. Bertolero. 1970. Gustatory, salivary, and oral thermal responses to solutions of sodium chloride at four temperatures. Percept. Psychophys. 8:69-75. 
Paulus, K., and A. M. Reisch. 1980. The influence of temperature on the threshold values of primary tastes. Chem. Senses 5:11-20.

Pearce, J. H., B. Korth, and C. B. Warren. 1986. Evaluation of three scaling methods for hedonics. J. Sens. Stud. 1:27-46.

Rosett, T. R., S. L. Kendregan, Y. Gao, S. J. Schmidt, and B. P. Klein. 1996. Thickening agents effects on sodium binding, salt taste and other taste qualities of soup systems. J. Food Sci. 61:1099-1104.

Rosett, T. R., L. L. Shirley, B. P. Klein, and S. J. Schmidt. 1994. Na+ binding as measured by ${ }^{23} \mathrm{Na}$ nuclear magnetic resonance spectroscopy influences the perception of saltiness in gum solutions. J. Food Sci. 59:206-210.

Rosett, T. R., Z. Wu, S. J. Schmidt, D. M. Ennis, and B. P. Klein. 1995. KCl, $\mathrm{CaCl}^{2}, \mathrm{Na}^{+}$binding and salt taste of gum systems. J. Food Sci. 60:849-853., 867.

Shamil, S., L. J. Wyeth, and D. Kilcast. 1992. Flavour release and perception in reduced-fat foods. Food Qual. Prefer. 3:51-60.
Stampanoni, C. R., and A. C. Noble. 1991. The influence of fat, acid, and salt on the perception of selected taste and texture attributes of cheese analogs - A scalar study. J. Texture Stud. 22:367-380.

Stehlin, D. 1993. A little "lite" reading. FDA Consum. 27:1-3.

USDA. 2005. Dietary Guidelines for Americans: Chapter 8: Sodium and potassium. US Department of Health and Human Services; USDA. Accessed February 27, 2009. www.healthierus.gov/dietaryguidelines.

Wendin, K., M. Langton, L. Caous, and G. Hall. 2000. Dynamic analyses of sensory and microstructural properties of cream cheese. Food Chem. 71:363-378.

Wyatt, C. J. 1983. Acceptability of reduced sodium in breads, cottage cheese, and pickles. J. Food Sci. 48:1300-1302. 